\title{
Gamma Knife surgery for patients with jugular foramen schwannomas: a multiinstitutional retrospective study in Japan
}

\author{
Toshinori Hasegawa, MD, ${ }^{1}$ Takenori Kato, MD, ${ }^{1}$ Yoshihisa Kida, MD, ${ }^{2}$ Ayaka Sasaki, MD, ${ }^{3}$ \\ Yoshiyasu Iwai, MD, PhD, ${ }^{4}$ Takeshi Kondoh, MD, ${ }^{5}$ Takahiko Tsugawa, MD, ${ }^{6}$ Manabu Sato, MD, ${ }^{7}$ \\ Mitsuya Sato, MD, ${ }^{8}$ Osamu Nagano, MD, ${ }^{9}$ Kotaro Nakaya, MD, ${ }^{10}$ Kiyoshi Nakazaki, MD, ${ }^{11}$ \\ Tadashige Kano, MD, ${ }^{12}$ Koichi Hasui, MD,13 Yasushi Nagatomo, MD, ${ }^{14}$ Soichiro Yasuda, MD, ${ }^{15}$ \\ Akihito Moriki, MD, ${ }^{16}$ Toru Serizawa, MD, ${ }^{17}$ Seiki Osano, MD, ${ }^{18}$ and Akira Inoue, MD ${ }^{19}$
}

\begin{abstract}
${ }^{1}$ Department of Neurosurgery, Komaki City Hospital, Komaki; ${ }^{2}$ Department of Neurosurgery, Kamiiida Daiichi General Hospital, Nagoya; ${ }^{3}$ Department of Neurosurgery, Tokyo Women's Medical University, Tokyo; ${ }^{4}$ Department of Neurosurgery, Osaka City General Hospital, Osaka; ${ }^{5}$ Department of Neurosurgery, Shinsuma Hospital, Kobe; ${ }^{6}$ Nagoya Radiosurgery Center, Nagoya Kyoritsu Hospital, Nagoya; ${ }^{7}$ Department of Neurosurgery, Rakusai Shimizu Hospital, Kyoto; ${ }^{8}$ Department of Neurosurgery, Kitanihon Neurosurgical Hospital, Gosen; ${ }^{\circ}$ Department of Neurosurgery, Chiba Cerebral and Cardiovascular Center, Ichihara; ${ }^{10}$ Department of Neurosurgery, Atami Tokoro Memorial Hospital, Atami; ${ }^{11}$ Department of Neurosurgery, Brain Attack Center, Ota Memorial Hospital, Fukuyama; ${ }^{2}$ Department of Neurosurgery, Institute of Brain and Blood Vessels, Mihara Memorial Hospital, Isesaki; ${ }^{13}$ Department of Neurosurgery, Okamura Isshindow Hospital, Okayama; ${ }^{14}$ Department of Neurosurgery, Kouseikai Takai Hospital, Tenri; ${ }^{15}$ Department of Neurosurgery, Shiroyama Hospital, Habikino; ${ }^{16}$ Department of Neurosurgery, Mominoki Hospital, Kochi; ${ }^{17}$ Tokyo Gamma Unit Center, Tsukiji Neurological Clinic, Tokyo; ${ }^{18}$ Department of Neurosurgery, Shonan Fujisawa Tokushukai Hospital, Fujisawa; and ${ }^{19}$ Department of Neurosurgery, Yamagata Prefectural Central Hospital, Yamagata, Japan
\end{abstract}

OBJECTIVE This study aimed to explore the efficacy and safety of stereotactic radiosurgery in patients with jugular foramen schwannomas (JFSs).

METHODS This study was a multiinstitutional retrospective analysis of 117 patients with JFSs who were treated with Gamma Knife surgery (GKS) at 18 medical centers of the Japan Leksell Gamma Knife Society. The median age of the patients was 53 years. Fifty-six patients underwent GKS as their initial treatment, while 61 patients had previously undergone resection. At the time of GKS, 46 patients (39\%) had hoarseness, 45 (38\%) had hearing disturbances, and $43(36 \%)$ had swallowing disturbances. Eighty-five tumors $(73 \%)$ were solid, and $32(27 \%)$ had cystic components. The median tumor volume was $4.9 \mathrm{~cm}^{3}$, and the median prescription dose administered to the tumor margin was 12 Gy. Five patients were treated with fractionated GKS and maximum and marginal doses of 42 and $21 \mathrm{~Gy}$, respectively, using a 3-fraction schedule.

RESULTS The median follow-up period was 52 months. The last follow-up images showed partial remission in 62 patients (53\%), stable tumors in 42 patients (36\%), and tumor progression in 13 patients (11\%). The actuarial 3- and 5-year progression-free survival (PFS) rates were $91 \%$ and $89 \%$, respectively. The multivariate analysis showed that pre-GKS brainstem edema and dumbbell-shaped tumors significantly affected PFS. During the follow-up period, 20 patients (17\%) developed some degree of symptomatic deterioration. This condition was transient in $12(10 \%)$ of these patients and persistent in 8 patients (7\%). The cause of the persistent deterioration was tumor progression in 4 patients (3\%) and adverse radiation effects in 4 patients (3\%), including 2 patients with hearing deterioration, 1 patient with swallowing disturbance, and 1 patient with hearing deterioration and hypoglossal nerve palsy. However, the preexisting hoarseness and swallowing disturbances improved in $66 \%$ and $63 \%$ of the patients, respectively.

CONCLUSIONS GKS resulted in good tumor control in patients with either primary or residual JFSs. Although some patients experienced some degree of symptomatic deterioration after treatment, persistent adverse radiation effects were seen in only $3 \%$ of the entire series at the last follow-up. Lower cranial nerve deficits were extremely rare adverse

ABBREVIATIONS GKS = Gamma Knife surgery; JFS = jugular foramen schwannoma; PFS = progression-free survival; SRS = stereotactic radiosurgery. SUBMITTED May 18, 2015. ACCEPTED August 27, 2015.

INCLUDE WHEN CITING Published online January 22, 2016; DOI: 10.3171/2015.8.JNS151156. 
radiation effects, and preexisting hoarseness and swallowing disturbances improved in two-thirds of patients. These results indicated that GKS was a safe and reasonable alternative to surgical resection in selected patients with JFSs.

http://thejns.org/doi/abs/10.3171/2015.8.JNS151156

KEY WORDS functional outcome; Gamma Knife; jugular foramen schwannoma; stereotactic radiosurgery; tumor control

$\mathrm{T}$ o date, resection has been the primary course of treatment for patients harboring jugular foramen schwannoma (JFS). Because JFSs are benign slowgrowing tumors, complete tumor resection is the ideal curative treatment. However, most patients develop neurological deterioration as a result of mechanical cranial nerve injuries that occur during surgery. ${ }^{1,9,29,31,32}$ Even if the tumor is completely resected, the neurological deterioration, including swallowing disturbances and vocal cord paralysis, significantly affects the patient's quality of life. Currently, the complete removal of JFSs without any cranial nerve injuries is challenging, even for highly experienced neurosurgeons and with recent advances in skull base microsurgical and neuromonitoring techniques. During the last 3 decades, stereotactic radiosurgery (SRS) has emerged as a minimally invasive treatment that is effective for various brain tumors as well as arteriovenous malformations. However, to the best of our knowledge, there is little information about the outcomes of patients with JFSs who were treated with SRS because of the rarity of the disease..$^{10,18,22}$ Accordingly, we aimed to evaluate the safety and efficacy of SRS in patients with JFSs in this multiinstitutional retrospective study.

\section{Methods}

\section{Patient Characteristics}

This multiinstitutional retrospective study was conducted at 18 medical centers of the Japan Leksell Gamma Knife Society. The data on the patients with JFSs who were treated with Gamma Knife surgery (GKS) between 1991 and 2013 were obtained from individual institutional review board-approved databases. Each of the 18 participating centers had institutional review board approval to combine and analyze the data. The inclusion criteria for tumors without histological confirmation were as follows: 1) The tumor was verified to be confined to the course of the glossopharyngeal, vagus, and accessory nerves with intra- and/or extracranial extension through the jugular foramen on thin-slice, axial T1-weighted images and constructive interference on steady-state images (or fast imaging employing steady-state acquisition); and 2) the tumor was presumed to be a JFS on MRI scans because it did not have the salt-and-pepper appearance that is typical of glomus jugulare tumors ${ }^{7}$ or the dural tail sign that indicates a meningioma. ${ }^{27}$ Tumors that were diagnosed as JFSs by microsurgical observations were also included in this study. Patients with neurofibromatosis Type 2 and those who did not undergo follow-up for 1 year or longer were excluded. A total of 117 patients with JFSs were eligible for this study. Of these, 61 patients who had previously undergone surgeries were diagnosed by microsurgical observation. Forty-three patients underwent GKS for residual tumors after microsurgery, whereas 18 patients underwent GKS for tumor recurrence. GKS was the initial treatment in 56 patients, all of whom met the inclusion criteria. Of these 56 patients, 7 had growing tumors on serial radiological images. Twenty-five patients $(21 \%)$ had growing tumors during a mean observation period of 43 months, and 92 patients (79\%) had no evidence of tumor growth before GKS. No patient underwent previous radiotherapy. The patient characteristics are shown in Table 1. The initial symptoms were hearing disturbances in 31 patients (26\%); hoarseness in 26 patients $(22 \%)$; swallowing disturbances in 18 patients $(15 \%)$; gait disturbances in 17 patients (15\%); dizziness in 11 patients (9\%); hypoglossal nerve disturbances in 8 patients $(7 \%)$; headache in 7 patients $(6 \%)$; hypesthesia in 3 patients (3\%); tinnitus in 2 patients (2\%); and facial palsy, facial spasm, dysgeusia, dysarthria, and trachelophyma in 1 patient $(1 \%)$ each. Fourteen patients $(12 \%)$ were incidentally found when checking on other complaints. The symptoms at the time of the GKS are shown in Table 2.

TABLE 1. Characteristics in 117 patients with JFSs who were treated using GKS*

\begin{tabular}{cc}
\hline \multicolumn{1}{c}{ Characteristics } & Value \\
\hline Age (yrs) & $17-85$ \\
\hline Range & 53 \\
\hline Median & $51(44)$ \\
\hline Sex & $66(56)$ \\
\hline Male & \\
\hline Female & $35(30)$ \\
\hline Karnofsky Performance Status score & $57(49)$ \\
\hline 100 & $15(13)$ \\
\hline 90 & $5(4)$ \\
\hline 80 & $4(3)$ \\
\hline 70 & $1(1)$ \\
\hline 60 & \\
\hline 50 & $56(48)$ \\
\hline Prior tumor resection & $49(42)$ \\
\hline 0 & $12(10)$ \\
\hline 1 & $0(0)$ \\
\hline 2 &
\end{tabular}

* Values are shown as number of patients (\%) unless otherwise indicated. 
Twenty-one patients, including 5 patients who had previously undergone surgeries, had no symptoms at the time of GKS but they wished to be treated with prophylactic GKS before the development of neurological deficits caused by further tumor growth when sufficient informed consent was provided. Sixty-one tumors (52\%) were located on the left side, and 56 (48\%) were on the right side. Eighty-five tumors $(73 \%)$ were solid, and 32 tumors $(27 \%)$ had cystic components. The tumor locations were classified into 4 types, as described by Martin et al. (Table 3, Fig. 1). ${ }^{18}$ Brainstem compression was found in 35 patients (30\%), 6 of whom $(5 \%)$ showed brainstem edema at the time of the GKS.

\section{Radiosurgical Techniques}

GKS was performed with the aid of a Leksell Coordinate Frame G (Elekta AB). After the administration of a mild sedative and local anesthesia, the frame was applied. Patient treatment was planned with the KULA system (Elekta AB) until 1996 and GammaPlan software (Elekta $A B$ ) thereafter. In all participating centers, thin-slice, axial T1-weighted or spoiled gradient echo images with gadolinium enhancement were used for tumor delineation.

TABLE 2. Symptomatic presentation at the time of GKS $(n=117)$

\begin{tabular}{|c|c|}
\hline Symptom & No. of Patients (\%) \\
\hline Hoarseness & $46(39)$ \\
\hline Hearing disturbance* & $45(38)$ \\
\hline Class II & 11 \\
\hline Class III & 11 \\
\hline Class IV & 1 \\
\hline Class V & 10 \\
\hline Unknown & 12 \\
\hline Swallowing disturbance & $43(37)$ \\
\hline Hypoglossal nerve palsy & $23(20)$ \\
\hline Gait disturbance & $19(16)$ \\
\hline Facial palsy† & $13(11)$ \\
\hline Grade II & 5 \\
\hline Grade IV & 3 \\
\hline Unknown & 5 \\
\hline Sensory disturbance & $7(6)$ \\
\hline Dizziness & $2(2)$ \\
\hline Hemiparesis & $1(1)$ \\
\hline Facial spasm & $1(1)$ \\
\hline Sternocleidomastoid muscle weakness & $1(1)$ \\
\hline Trapezius muscle weakness & $1(1)$ \\
\hline Dysarthria & $1(1)$ \\
\hline Dysgeusia & $1(1)$ \\
\hline Palatal paralysis & $1(1)$ \\
\hline Tinnitus & $1(1)$ \\
\hline Trachelophyma & $1(1)$ \\
\hline Headache & $1(1)$ \\
\hline Asymptomatic & $21(18)$ \\
\hline
\end{tabular}

TABLE 3. Tumor classification on the basis of tumor location

\begin{tabular}{clc}
\hline $\begin{array}{c}\text { Tumor } \\
\text { Type }\end{array}$ & \multicolumn{1}{c}{ Tumor Type } & $\begin{array}{c}\text { No. of } \\
\text { Tumors (\%) }\end{array}$ \\
\hline A & Primary intracranial & $28(24)$ \\
\hline B & Jugular foramen w/ intracranial extension & $38(32)$ \\
\hline C & Primary extracranial w/ foraminal extension & $12(10)$ \\
\hline D & Intra-/extracranial extension (dumbbell shape) & $39(33)$ \\
\hline
\end{tabular}

No treatment was planned using CT alone in this study. After dose planning, the patients were treated with Gamma Knife models B, C, 4C, or Perfexion (Elekta AB) at the participating centers. The dose selection was decided by each participating center. The prescription dose to the tumor margin was likely to be relatively high in the early days, but 11 to 13 Gy was typically administered to recently treated patients. Basically, the doses to the critical structures, such as the brainstem, were restricted to $15 \mathrm{~Gy}$ or less. The median tumor volume was $4.9 \mathrm{~cm}^{3}$ (range 0.1 $45.8 \mathrm{~cm}^{3}$ ). The median maximum dose was $24 \mathrm{~Gy}$ (range 20-40 Gy), and the median marginal dose was 12 Gy (range 10-18 Gy), which was prescribed at a median isodose line of $50 \%$ (range $45 \%-60 \%$ ). At 1 center, 5 patients were treated with total maximum and marginal doses of 42 and 21 Gy, respectively, with 3-session GKS because of relatively large tumor volumes.
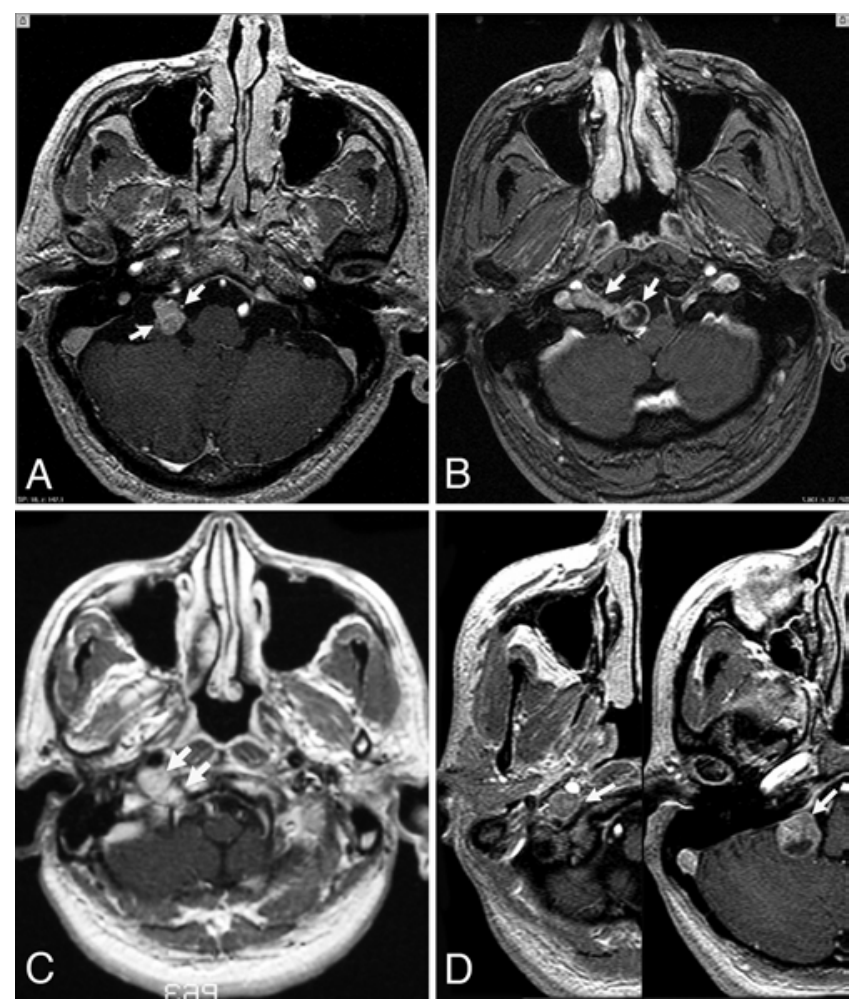

FIG. 1. JFSs were classified into 4 categories on the basis of tumor location and are shown on T1-weighted axial images with gadolinium enhancement (arrows). A: Type A: primary intracranial tumors. B: Type B: jugular foramen tumors with intracranial extension. C: Type C: primary extracranial tumors with foraminal extension. D: Type D: dumbbellshaped tumors with intraextracranial extension. 


\section{Follow-Up Evaluations}

Imaging studies were performed at each center at an interval of 3 to 6 months during the first 3 years and annually thereafter. The clinical data, including the neurological signs, were evaluated simultaneously. The clinical follow-up data were obtained from their referring doctors. Based on the radiological follow-up studies with thin-slice, T1-weighted axial images with gadolinium enhancement, complete remission was defined as tumor disappearance, partial remission was defined as a volume reduction of $25 \%$ or more, no change was defined as a volume reduction or increase less than $25 \%$, and tumor progression was defined as a volume increase of $25 \%$ or more. In addition, transient expansion was defined as the occurrence of any enlargement before tumor shrinkage.

\section{Statistical Analysis}

Progression-free survival (PFS) after GKS was calculated using the Kaplan-Meier estimator. To analyze the influence of prognostic factors on PFS, we assessed the following data: age ( $<65$ vs $\geq 65$ years), sex (male vs female), prior surgeries (yes vs no), tumor growth before GKS (growing tumor vs no evidence of tumor growth), tumor nature (solid vs cyst), tumor type (dumbbell-shaped [Type D] vs others [Types A, B, or C]), marginal dose (s 12 Gy vs $>12 \mathrm{~Gy})$, tumor volume $\left(\leq 5 \mathrm{~cm}^{3}\right.$ vs $\left.>5 \mathrm{~cm}^{3}\right)$, and radiological findings at the time of GKS, including brainstem compression (yes vs no) and brainstem edema (yes vs no). For the 5 patients who were treated with 3 -session GKS, the maximum and marginal doses were calculated as $25 \mathrm{~Gy}$ and $13 \mathrm{~Gy}$, respectively, based on a linear-quadratic model that assumed an $\alpha / \beta$ ratio of 2 Gy for JFS. The factors affecting PFS were assessed using the logrank test in the univariate analysis and a Cox proportional regression model in the multivariate analysis, in which the continuous variables were age, marginal dose, and tumor volume. A final multivariate analysis was calculated with a stepwise forward selection method. Hazard ratios were reported with $95 \%$ confidence intervals. The statistical analyses were performed using SPSS version 21.0 for Windows (IBM Corp.); $\mathrm{p}$ values $<0.05$ were considered statistically significant.

\section{Results}

The mean and median clinical follow-up periods were 80 and 52 months, respectively (range 12-248 months). Fifty-seven (49\%) and 33 (28\%) patients were followed for 5 and 10 years or longer, respectively. The mean and median radiological follow-up periods were 72 and 48 months, respectively (range 6-247 months). During the followup period, 1 patient died of pneumonia at 22 months after GKS, 1 patient died of leukemia at 59 months after GKS, and 1 patient died of a cerebellar hemorrhage at 174 months after GKS.

\section{Tumor Control}

On the last follow-up imaging evaluations, partial remission was observed in 62 patients (53\%), no change was observed in 42 patients (36\%), and tumor progression was observed in 13 patients (11\%). The actuarial 3-, 5-, and 10year PFS rates were $91 \%, 89 \%$, and $83 \%$, respectively (Fig. 2). Transient expansion was evaluated in 94 patients. Thirteen patients were excluded due to tumor progression, and 10 patients were excluded because no radiological images were available that were taken within a year after treatment. Transient expansion occurred in 31 patients (33\%) with a median interval of 6 months after GKS.

\section{Factors Affecting PFS}

In the univariate analysis, brainstem edema at the time

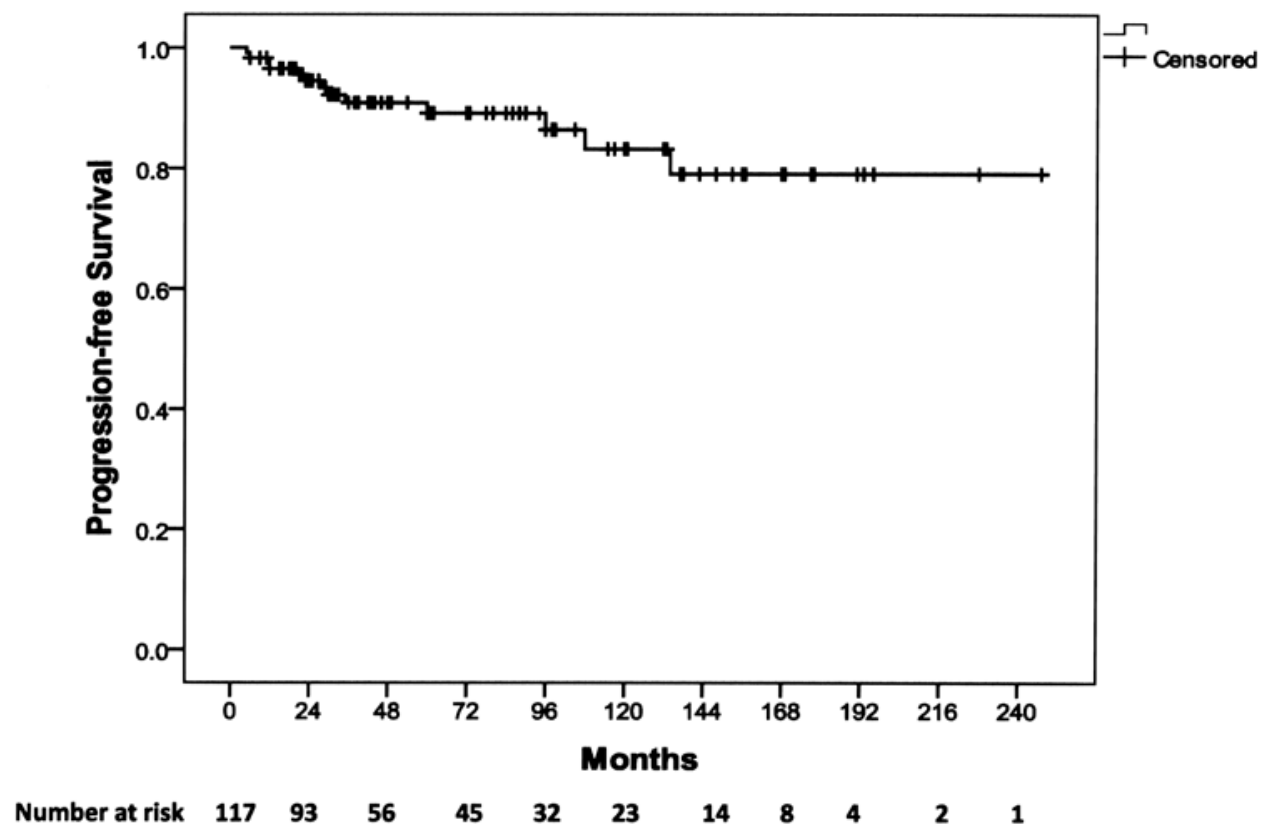

FIG. 2. Kaplan-Meier curve showing PFS in 117 patients with JFS. The actuarial 3- and 5-year PFS rates were $91 \%$ and $89 \%$, respectively. 
of the GKS $(p=0.012)$, marginal dose $(p=0.016)$, and tumor type ( $p=0.036)$ were significantly related to PFS. In the multivariate analysis, brainstem edema at the time of the GKS and Type D tumors (dumbbell-shaped) were significantly related to treatment failure, with HRs of 6.188 (95\% CI 1.293-29.616; $\mathrm{p}=0.023$ ) and 3.189 (95\% CI $1.048-9.703 ; p=0.041$ ), respectively. There was no significant difference in PFS between Type A, B, and C tumors. The actuarial 3- and 5-year PFS rates in patients without pre-GKS brainstem edema were both $91 \%$ in comparison with $83 \%$ and $42 \%$, respectively, in patients with brainstem edema. Similarly, the actuarial 3- and 5-year PFS rates in patients with Type A, B, or C tumors were $96 \%$ and $93 \%$, respectively, in comparison with $81 \%$ for both rates in patients with Type $\mathrm{D}$ tumors.

\section{Salvage Treatment}

Of the 13 patients with tumor progression, 3 patients required craniotomies at 5, 21, and 108 months after GKS, respectively. All of these patients developed cysts. One of these 3 patients underwent staged surgeries for intra- and extracranial tumors at 21 and 24 months, respectively, and a second GKS for the residual tumor at 26 months. Two patients underwent repeat GKS at 30 and 35 months. For the 3 patients who required repeat GKS, good tumor control was achieved without any adverse radiation effects. The remaining 8 patients did not undergo any additional treatments. Three of these 8 patients, who had short follow-up periods of less than 2 years, were observed carefully because of the possibility that transient expansion would shrink in the near future. Another 3 of these 8 patients developed tumor progression without symptomatic deterioration at 28, 60, and 90 months, respectively. Two of these 3 patients retained their neurological function, with a halt in tumor growth until 164 and 168 months, whereas the patient with tumor enlargement at 28 months had no neurological deterioration until he died of leukemia at 59 months. The remaining 2 of these 8 patients developed tumor enlargement with symptomatic deterioration. Although 1 of these patients developed gait disturbance at 6 months, he refused any salvage treatment due to his advanced age of 77 years. The other patient had tumor enlargement that caused hearing deterioration at 134 months, but she refused any salvage treatment due to her advanced age of 76 years.

\section{Functional Outcomes}

The details of the functional outcomes are shown in Table 4. Of the 44 evaluated patients who had hoarseness at the time of GKS, 29 patients (66\%) exhibited improved hoarseness, 14 patients (32\%) remained stable, and 1 patient (2\%) had worsened at the last clinical follow-up examination. Although 1 patient exhibited newly developed hoarseness, the condition was transient. Of the 40 evaluated patients who had swallowing disturbances, 25 patients $(63 \%)$ showed improvements in swallowing function, 14 patients $(35 \%)$ remained stable, and 1 patient $(3 \%)$ worsened. Two patients showed newly developed swallowing disturbances, but the condition was transient in both. During the follow-up period, 20 (17\%) of 117 patients had some degree of symptomatic deterioration. The condition was transient in 12 patients (10\%) and persistent in 8 patients (7\%). Of the 8 patients with persistent deterioration, 4 patients (3\%) worsened due to tumor progression and 4 patients (3\%) worsened despite tumor regression. Of the latter 4 patients, 2 patients developed hearing disturbances, 1 patient developed swallowing disturbances, and 1 patient developed hearing disturbances and hypoglossal nerve palsy. These symptomatic deteriorations were considered adverse radiation effects.

\section{Discussion}

\section{Treatment Options}

The current treatment options for patients with JFSs include surveillance, resection, ${ }^{1-4,9,14,29,30-32}$ and radiation therapies, such as stereotactic radiotherapy ${ }^{6,20}$ or radiosurgery. $5,8,15,17,19,22,25,26,34$ To date, resection has been the mainstay treatment for patients with JFSs. However, it is very difficult, even for highly experienced neurosurgeons, to completely remove these tumors without any complications, despite the recent remarkable refinements in microsurgical techniques and neuromonitoring. The rarity and anatomical complexity of this disease make it much more difficult to determine how to resect the tumor safely. The number of tumors that are incidentally found in asymptomatic patients is likely to increase because of recent advances in imaging, such as CT and MRI. Particularly for these asymptomatic patients, neurological deterioration after resection could be a big issue because lower cranial nerve deficits are some of the most serious neurological disabilities. Some patients require tracheostomies for vocal cord paralysis and gastrostomas for swallowing disturbances. These common complications in patients with JFSs not only significantly worsen their quality of life but are also life threatening for elderly patients. According to a microsurgical series of 22 patients with JFS reported by Sanna et al., ${ }^{31}$ half of the patients had worse glossopharyngeal and vagus nerve function postoperatively. More recently, Sedney et al. documented a conservative operative technique of near-total resection that significantly decreased glossopharyngeal and vagus nerve deficits that persisted postoperatively in comparison with radical gross-total resection. ${ }^{32}$ Consequently, their surgical strategy for JFSs was changed from total resection to near-total resection. Recent surgical series of JFSs are shown in Table 5.

During the last 3 decades, SRS has emerged as a possible treatment option. There are several reports on the safety and efficacy of SRS for patients with JFSs, ${ }^{18,22}$ but these studies generally included a small number of patients because of the rarity of this disease. To the best of our knowledge, this is the largest study of JFSs that were treated with SRS. According to the results of 35 JFSs that were treated with GKS and reported by Martin et al.., ${ }^{18}$ the actuarial 5- and 10-year tumor control rates were $97 \%$ and $94 \%$, respectively, with a median follow-up period of 83 months. However, our results were not as good as theirs. In our study, 13 of 117 patients developed tumor progression, with a median interval of 28 months after GKS. Of these 13 patients, 3 patients seemed to exhibit transient expansion because of the short follow-up periods, which 


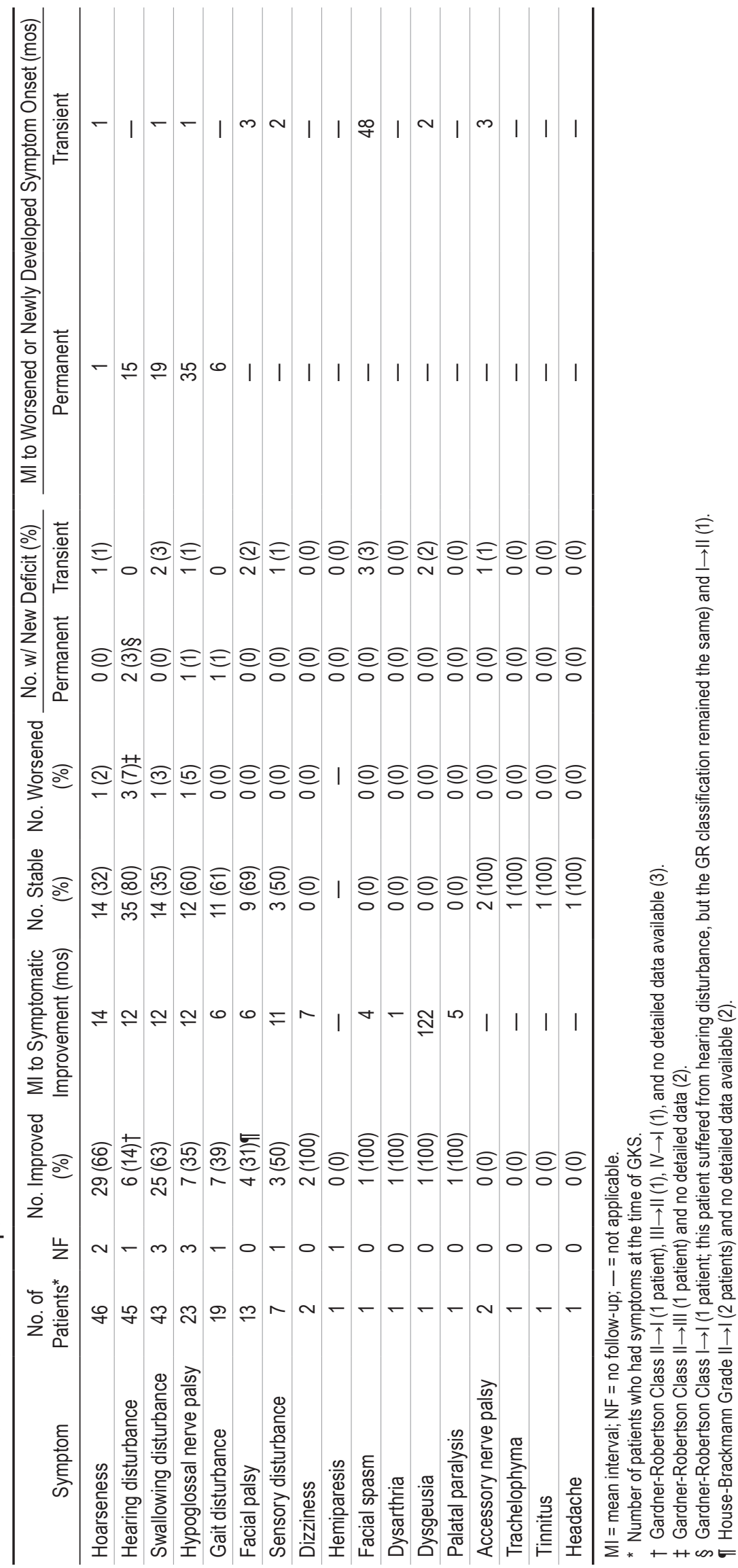




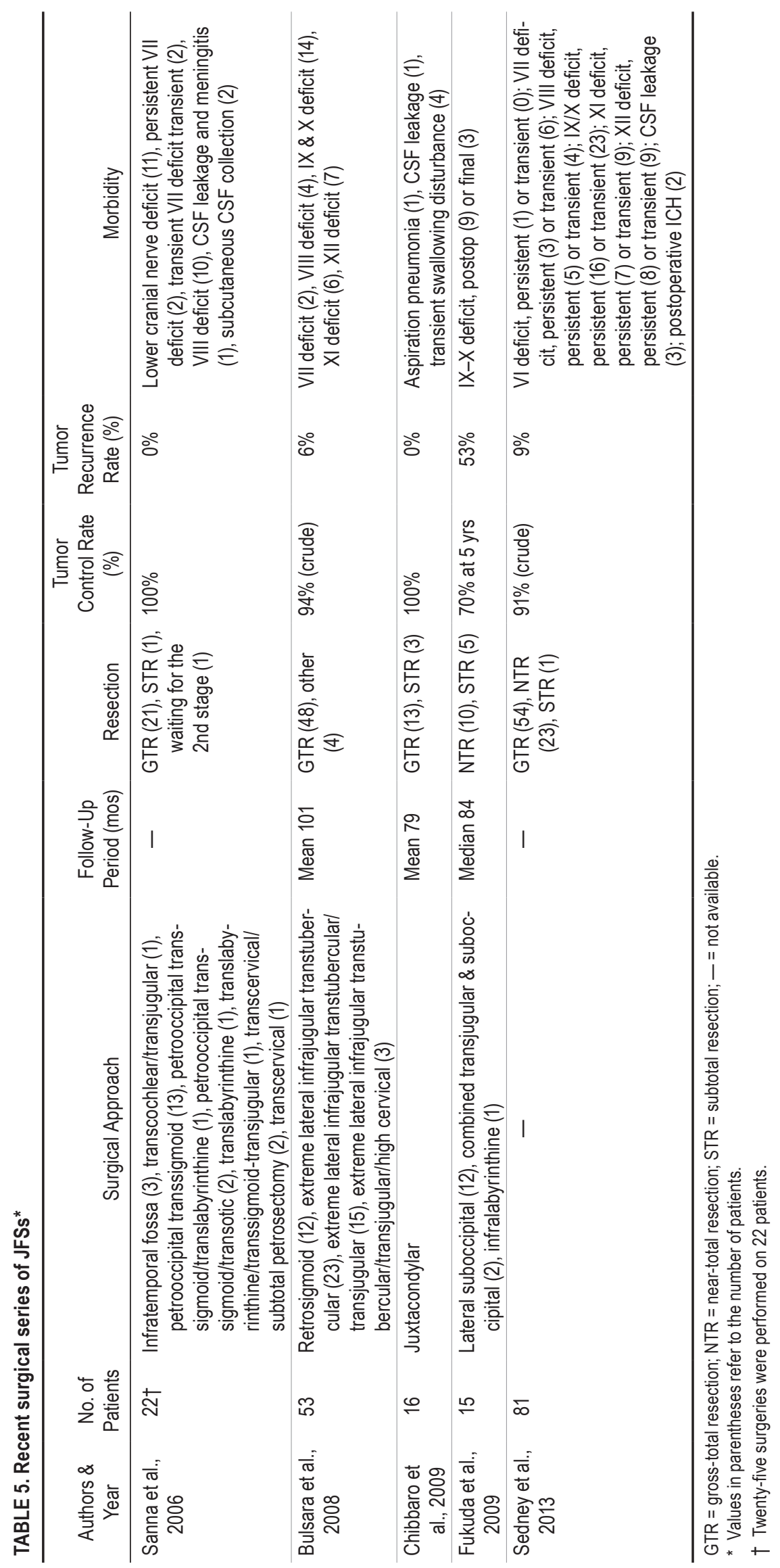


were 2 years or less. Therefore, it is possible that the tumors naturally decrease in size in the immediate future, as transient expansion was seen in one-third of the patients who exhibited good tumor control at their last follow-up examination. The other 2 patients had tumor progression at 60 and 96 months. However, subsequently, the tumors did not grow anymore, and no symptomatic deterioration developed over 5 years after tumor progression. Eventually, only 5 patients required secondary treatments such as resection or repeat GKS. Interestingly, all 3 patients who required resection had newly developed cysts or preexisting cyst enlargement. Such radiological changes have also been found in patients with vestibular schwannomas who were treated with SRS, ${ }^{12}$ and these radiological changes are some of the most common causes that require craniotomy as a salvage treatment. Although the mechanism of cyst formation is still unclear, it has been postulated that intratumoral cyst formation is caused by radiationinduced repeat microbleeding or increased vascular permeability. ${ }^{21,24}$ Pre-GKS brainstem edema from tumor compression and dumbbell-shaped tumors significantly affected treatment failure in this study. This result was not surprising because even slight tumor expansion easily induces further brainstem edema that results in neurological deficits, such as gait disturbance. Therefore, large tumors with severe brainstem compression that causes perifocal edema are not suitable for primary treatment by SRS, but instead should be treated with resection. In addition, complex tumor shapes, such as dumbbell-shaped tumors, are a significant factor in dose planning, as insufficient tumor coverage results in a high rate of treatment failure. On the other hand, a radiological finding of tumor growth before GKS was not related to PFS significantly. Approximately $80 \%$ of the patients included in this study had no evidence of tumor growth before GKS because of immediate treatment after diagnosis or surgery. However, these tumors may have been growing before initial treatment because they were usually found when checking on neurological deterioration such as hoarseness, swallowing disturbance, or hearing disturbance, except for the 14 patients whose tumors were incidentally found without any symptoms.

\section{Functional Outcomes and Adverse Radiation Effects}

One striking finding regarding the functional outcomes after GKS in this study was the high rate of functional improvement, especially for swallowing disturbances and hoarseness. Two-thirds of the patients who had suffered from swallowing disturbances and/or hoarseness at the time of the GKS exhibited improvements, with a mean interval of 1 year after GKS, and these symptoms worsened in only 1 patient. Surprisingly, no patient had newly developed swallowing disturbances or hoarseness at their last clinical follow-up examination. Finally, 8 (7\%) of the 117 patients developed persistent functional deterioration. Of these 8 patients, the complications from adverse radiation effects were hearing deterioration in 2 patients, swallowing disturbances in 1 patient, and hearing deterioration and hypoglossal nerve palsy in 1 patient. Similarly, Martin et al. reported in their radiosurgical series of $35 \mathrm{JFSs}$ that preexisting cranial neuropathies improved in $20 \%$ of patients and worsened in only 1 patient who had tumor enlargement. ${ }^{18}$ Those functional results seem to be superior to those after the resections in the present patients. As shown in Table 5, cranial nerve injuries seemed to be impossible to completely avoid with total tumor resection. It should be noted that once the lower cranial nerves are sacrificed during surgery, patients will continue to suffer from swallowing disturbances and vocal cord paralysis that require gastrostomies and tracheostomies for the rest of the patients' lives. Although a $17 \%$ morbidity rate, including transient deficits, after GKS may not be so low, we believe that such risk would be acceptable for patients with intractable tumors like JFSs, considering the higher morbidity rates of microsurgical series.

\section{Treatment Strategy}

When brainstem edema with severe brainstem compression by the tumor is found on radiological images, the tumor should be removed first. However, it is not necessary to conduct a complete tumor resection because good tumor control with a low risk of complications can be obtained with GKS as the adjuvant treatment. At the time of surgery, it is important to relieve the brainstem compression while retaining neurological function. Even if the patient suffers from swallowing disturbances or hoarseness at presentation, these symptoms improve in two-thirds of patients treated with GKS. In cases with asymptomatic JFSs, surveillance may be a reasonable treatment choice, but prophylactic GKS can also be an acceptable treatment option if sufficient informed consent is provided. As shown in this study, newly developed cranial nerve injuries due to adverse radiation effects are extremely rare unless the tumor continues to grow. When the tumor is too large to be treated by a single session of radiosurgery and the patient is unsuitable for surgery because of advanced age or a comorbidity, multisession GKS could be a reasonable alternative in order to avoid radiation injuries to critical structures, including the brainstem and cranial nerves.

\section{Study Limitations}

First, this study was a retrospective multiinstitutional study; therefore, patient selection, the radiosurgical techniques such as the prescription dose to the tumor, the dose constraints for the critical structures, and follow-up imaging studies for tumor assessment may have varied between participating centers. In addition, this study included 5 patients who were treated with 3 -session GKS performed at 1 center because of relatively large tumor volumes. These biases may have impacted our results. Second, almost half of the patients underwent GKS as their initial treatment and did not have histological confirmation of the tumor. Most were diagnosed based on the typical radiological findings that were confined to the course of the ninth, tenth, and eleventh cranial nerves, and that usually extended from the jugular foramen into the intra- and/or extracranial region without a dural tail sign that is typical of meningiomas and the hypervascularity that is typical of glomus jugular tumors. However, it is possible that other tumors, such as glomus tumors, meningiomas, chordomas, chondrosarcomas, other schwannomas, or malignant tumors, were included in this study. ${ }^{28}$ Nevertheless, we believe that histological confirmation may be unnecessary, particularly for patients 
with advanced age, comorbidity, or those who refuse surgery, because such tumors are also good candidates for GKS, as has been reported by many investigators. ${ }^{11-13,16,23,33}$ Lastly, the follow-up period was too short to draw conclusions about the efficacy of SRS, especially for young patients. Hence, further follow-up data are necessary to clarify the long-term outcomes, including those related to tumor control, neurological function, and adverse radiation effects such as cyst formation or malignant change.

\section{Conclusions}

GKS contributed to good tumor control in the majority of the patients with either primary or residual JFSs. Although $17 \%$ of the patients experienced some degree of symptomatic deterioration after treatment, persistent adverse radiation effects were seen in only $3 \%$ of the entire series at the last follow-up. Lower cranial nerve deficits as adverse radiation effects were extremely rare, and two-thirds of the patients exhibited improvements in the preexisting hoarseness or swallowing disturbances. When tumors compress the brainstem with perifocal edema, safe tumor resections that spare the lower cranial nerves are recommended first. If the tumor persists, adjuvant GKS can be safely applied for good tumor control. Our results indicated that GKS was a safe and reasonable alternative to resection in select patients with primary or residual JFSs.

\section{Acknowledgments}

We thank Motohiro Hayashi, MD, Department of Neurosurgery, Tokyo Women's Medical University, Kazuyasu Aita, MD, Department of Neurosurgery, Kyoto Prefectural University of Medicine, Masahiro Minami, MD, and Naoya Ukita, MD, Department of Neurosurgery, Okayama East Neurosurgery Clinic, for assistance with data acquisition.

\section{References}

1. Bulsara KR, Sameshima T, Friedman AH, Fukushima T: Microsurgical management of 53 jugular foramen schwannomas: lessons learned incorporated into a modified grading system. J Neurosurg 109:794-803, 2008

2. Cavalcanti DD, Martirosyan NL, Verma K, Safavi-Abbasi S, Porter RW, Theodore N, et al: Surgical management and outcome of schwannomas in the craniocervical region. J Neurosurg 114:1257-1267, 2011

3. Chibbaro S, Mirone G, Makiese O, Bresson D, George B: Dumbbell-shaped jugular foramen schwannomas: surgical management, outcome and complications on a series of 16 patients. Neurosurg Rev 32:151-159, 2009

4. Cho YS, So YK, Park K, Baek CH, Jeong HS, Hong SH, et al: Surgical outcomes of lateral approach for jugular foramen schwannoma: postoperative facial nerve and lower cranial nerve functions. Neurosurg Rev 32:61-66, 2009

5. Choi CYH, Soltys SG, Gibbs IC, Harsh GR, Sakamoto GT, Patel DA, et al: Stereotactic radiosurgery of cranial nonvestibular schwannomas: results of single- and multisession radiosurgery. Neurosurgery 68:1200-1208, 2011

6. Collen C, Ampe B, Gevaert T, Moens M, Linthout N, De Ridder M, et al: Single fraction versus fractionated linacbased stereotactic radiotherapy for vestibular schwannoma: a single-institution experience. Int J Radiat Oncol Biol Phys 81:e503-e509, 2011

7. Eldevik OP, Gabrielsen TO, Jacobsen EA: Imaging findings in schwannomas of the jugular foramen. AJNR Am J Neuroradiol 21:1139-1144, 2000
8. Elsharkawy M, Xu Z, Schlesinger D, Sheehan JP: Gamma Knife surgery for nonvestibular schwannomas: radiological and clinical outcomes. J Neurosurg 116:66-72, 2012

9. Fukuda M, Oishi M, Saito A, Fujii Y: Long-term outcomes after surgical treatment of jugular foramen schwannoma. Skull Base 19:401-408, 2009

10. Hasegawa T: Stereotactic radiosurgery for nonvestibular schwannomas. Neurosurg Clin N Am 24:531-542, 2013

11. Hasegawa T, Ishii D, Kida Y, Yoshimoto M, Koike J, Iizuka $\mathrm{H}$ : Gamma Knife surgery for skull base chordomas and chondrosarcomas. J Neurosurg 107:752-757, 2007

12. Hasegawa T, Kida Y, Kato T, Iizuka H, Kuramitsu S, Yamamoto T: Long-term safety and efficacy of stereotactic radiosurgery for vestibular schwannomas: evaluation of 440 patients more than 10 years after treatment with Gamma Knife surgery. J Neurosurg 118:557-565, 2013

13. Kano H, Lunsford LD: Stereotactic radiosurgery of intracranial chordomas, chondrosarcomas, and glomus tumors. Neurosurg Clin N Am 24:553-560, 2013

14. Kaye AH, Hahn JF, Kinney SE, Hardy RW Jr, Bay JW: Jugular foramen schwannomas. J Neurosurg 60:1045-1053, 1984

15. Kimball MM, Foote KD, Bova FJ, Chi Y-Y, Friedman WA: Linear accelerator radiosurgery for nonvestibular schwannomas. Neurosurgery 68:974-984, 2011

16. Liscak R, Urgosik D, Chytka T, Simonova G, Novotny J Jr, Vymazal J, et al: Leksell Gamma Knife radiosurgery of the jugulotympanic glomus tumor: long-term results. J Neurosurg 121 Suppl:198-202, 2014

17. Mabanta SR, Buatti JM, Friedman WA, Meeks SL, Mendenhall WM, Bova FJ: Linear accelerator radiosurgery for nonacoustic schwannomas. Int J Radiat Oncol Biol Phys 43:545-548, 1999

18. Martin JJ, Kondziolka D, Flickinger JC, Mathieu D, Niranjan A, Lunsford LD: Cranial nerve preservation and outcomes after stereotactic radiosurgery for jugular foramen schwannomas. Neurosurgery 61:76-81, 2007

19. Muthukumar N, Kondziolka D, Lunsford LD, Flickinger JC: Stereotactic radiosurgery for jugular foramen schwannomas. Surg Neurol 52:172-179, 1999

20. Nishioka K, Abo D, Aoyama H, Furuta Y, Onimaru R, Onodera S, et al: Stereotactic radiotherapy for intracranial nonacoustic schwannomas including facial nerve schwannoma. Int J Radiat Oncol Biol Phys 75:1415-1419, 2009

21. Park CK, Kim DC, Park SH, Kim JE, Paek SH, Kim DG, et al: Microhemorrhage, a possible mechanism for cyst formation in vestibular schwannomas. J Neurosurg 105:576-580, 2006

22. Peker S, Sengöz M, Kılıç T, Pamir MN: Gamma knife radiosurgery for jugular foramen schwannomas. Neurosurg Rev 35:549-553, 2012

23. Pollock BE: Stereotactic radiosurgery in patients with glomus jugulare tumors. Neurosurg Focus 17(2):E10, 2004

24. Pollock BE, Brown RD Jr: Management of cysts arising after radiosurgery to treat intracranial arteriovenous malformations. Neurosurgery 49:259-265, 2001

25. Pollock BE, Foote RL, Stafford SL: Stereotactic radiosurgery: the preferred management for patients with nonvestibular schwannomas? Int J Radiat Oncol Biol Phys 52:10021007, 2002

26. Pollock BE, Kondziolka D, Flickinger JC, Maitz A, Lunsford LD: Preservation of cranial nerve function after radiosurgery for nonacoustic schwannomas. Neurosurgery 33:597-601, 1993

27. Qi ST, Liu Y, Pan J, Chotai S, Fang LX: A radiopathological classification of dural tail sign of meningiomas. J Neurosurg 117:645-653, 2012

28. Ramina R, Maniglia JJ, Fernandes YB, Paschoal JR, Pfeilsticker LN, Coelho Neto M, et al: Jugular foramen tumors: diagnosis and treatment. Neurosurg Focus 17(2):E5, 2004 
29. Ramina R, Maniglia JJ, Fernandes YB, Paschoal JR, Pfeilsticker LN, Coelho Neto M: Tumors of the jugular foramen diagnosis and management. Neurosurgery 57 (1 Suppl): 59-68, 2005

30. Samii M, Babu RP, Tatagiba M, Sepehrnia A: Surgical treatment of jugular foramen schwannomas. J Neurosurg 82: 924-932, 1995

31. Sanna M, Bacciu A, Falcioni M, Taibah A: Surgical management of jugular foramen schwannomas with hearing and facial nerve function preservation: a series of 23 cases and review of the literature. Laryngoscope 116:2191-2204, 2006

32. Sedney CL, Nonaka Y, Bulsara KR, Fukushima T: Microsurgical management of jugular foramen schwannomas. Neurosurgery 72:42-46, 2013

33. Starke RM, Williams BJ, Hiles C, Nguyen JH, Elsharkawy MY, Sheehan JP: Gamma knife surgery for skull base meningiomas. J Neurosurg 116:588-597, 2012

34. Zhang N, Pan L, Dai JZ, Wang BJ, Wang EM, Cai PW: Gamma knife radiosurgery for jugular foramen schwannomas. $\mathbf{J}$ Neurosurg 97 (5 Suppl):456-458, 2002

\section{Disclosures}

The authors report no conflict of interest concerning the materi- als or methods used in this study or the findings specified in this paper.

\section{Author Contributions}

Conception and design: Hasegawa, Kato, Kida. Acquisition of data: all authors. Analysis and interpretation of data: Hasegawa. Drafting the article: Hasegawa. Approved the final version of the manuscript on behalf of all authors: Hasegawa. Statistical analysis: Hasegawa. Study supervision: Hasegawa.

\section{Supplemental Information}

Previous Presentations

Portions of this work were presented in abstract form at the 16th meeting of of the Japanese Leksell Gamma Knife Society, Yokohama, Japan, February 22, 2015.

\section{Correspondence}

Toshinori Hasegawa, Department of Neurosurgery, Komaki City Hospital, Gamma Knife Center, 1-20 Jobushi, Komaki, Aichi Prefecture 485-8520, Japan. email: h-toshi@komakihp.gr.jp. 